\title{
Risco de crédito e eficiência técnica nas cooperativas de crédito brasileiras
}

\author{
LUA SYRMA ZaNIAH SANTOS ${ }^{1}$ \\ VALÉRIA GAMA FULLY BRESSAN ${ }^{2}$ \\ VILMAR RODRIGUES MOREIRA ${ }^{3}$ \\ ROMEU EUGÊNIO DE LIMA ${ }^{4}$
}

\author{
${ }^{1}$ Universidade Federal de Minas Gerais (UFMG) / FACULdAde de CIÊNCIAS ECONÔMICAS, Departamento de CIÊNCIAS CONTÁBEIS, \\ BELO HORIZONTE - MG, BRASIL \\ 2 Universidade Federal de Minas Gerais (UFMG) / Faculdade de CiÊnCIAS Econômicas, Programa de Pós-Graduação \\ EM CONTROLAdoria E CONTABILIDAdE DA FACE, BELO HORIZONTE - MG, BRASIL \\ ${ }^{3}$ Pontifícia Universidade Católica do Paraná (PuCPR) / Escola de Negócios, Programa de Pós-Graduação em Gestão \\ DE COOPERATIVAS, CURITIBA - PR, BRASIL \\ 4 Banco Central do Brasil, Belo Horizonte - MG, BRAsil
}

\section{Resumo}

Este estudo analisa a relação entre o risco de crédito e a eficiência das cooperativas de crédito brasileiras no período de 2008 a 2017. Utilizou-se o modelo de Data Envelopment Analysis em dois estágios para a obtenção dos escores de eficiência, com a análise de um modelo Tobit no segundo estágio. Foram consultados especialistas para a construção e a validação dos escores de eficiência, o que é uma contribuição desse estudo em relação aos demais. Constatou-se que, quanto maior o risco de crédito, menores os escores de eficiência. De igual modo, viu-se que as cooperativas de crédito que conseguem manter sua continuidade no mercado e diversificam seus produtos tiveram maiores escores de eficiência e, por consequência, geraram mais benefícios aos associados. Adicionalmente, as cooperativas devem se atentar no número de pontos de atendimentos e em períodos de recessão econômica. O aumento do número de pontos de atendimento reduz os escores de eficiência. Considerando o período de retração econômica brasileira medido no período de 2015 a 2017, verificou-se um impacto negativo nos escores de eficiência médios das cooperativas. Como limitação, os resultados são decorrentes de inputs e outputs selecionados de informações contábeis e financeiras, de modo que se sugere que novas variáveis relacionadas à dimensão social das cooperativas sejam incorporadas em outros estudos a fim de avaliar a eficiência global das cooperativas de crédito brasileiras.

Palavras-chave: Cooperativas de crédito. Eficiência. Risco de crédito. DEA. Tobit.

\section{Credit risk and technical efficiency in Brazilian credit unions}

\section{Abstract}

This study analyzed the relationship between credit risk and the efficiency of Brazilian credit unions in the period from 2008 to 2017 . The two-stage data envelopment analysis model was used to obtain efficiency scores, with the analysis of a Tobit model in the second stage. Specialists were consulted for the construction and validation of efficiency scores, which is a contribution of this study in relation to the others. It was found that the higher the credit risk, the lower the efficiency scores, and that credit unions that manage to maintain their continuity in the market and diversify their products had higher efficiency scores, consequently generating greater benefits to their members. Additionally, cooperatives must pay attention to the number of service points and periods of economic recession. The increase in the number of service points reduces efficiency scores. When considering the period of Brazilian economic downturn, measured from 2015 to 2017, there was a negative impact on the average efficiency scores of the cooperatives. As a limitation, it is reported that the results are derived from the inputs and outputs selected from accounting and financial information, and it is suggested that new variables related to the social dimension of cooperatives be incorporated into other studies to assess the overall efficiency of Brazilian credit unions.

Keywords: Credit unions. Efficiency. Credit risk. DEA. Tobit.

\section{Riesgo de crédito y eficiencia técnica en las cooperativas de crédito brasileñas}

\section{Resumen}

Este estudio analizó la relación entre el riesgo crediticio y la eficiencia de las cooperativas de ahorro y crédito brasileñas en el período de 2008 a 2017. El modelo de análisis de envoltura de datos en dos etapas se utilizó para obtener puntajes de eficiencia, con el análisis de un modelo tobit en la segunda etapa. Es de destacar que se consultó a especialistas para la construcción y validación de puntajes de eficiencia, lo que constituye una contribución de este estudio en relación con los demás. Se constató que cuanto mayor era el riesgo de crédito, menores eran los puntajes de eficiencia y que las cooperativas de ahorro y crédito que lograban mantener su continuidad en el mercado y diversificar sus productos tenían puntajes de eficiencia más altos, lo que generaba mayores beneficios para sus miembros. Además, las cooperativas deben prestar atención a la cantidad de puntos de servicio y períodos de recesión económica. El aumento del número de puntos de servicio reduce los puntajes de eficiencia. Y considerando el período de recesión económica brasileña, medido de 2015 a 2017, hubo un impacto negativo en los puntajes promedio de eficiencia de las cooperativas. Como limitación, se observó que los resultados se derivan de las entradas y salidas seleccionadas de información contable y financiera, y se sugiere incorporar nuevas variables relacionadas con la dimensión social de las cooperativas en otros estudios para evaluar la eficiencia global de las cooperativas de crédito brasileñas.

Palabras clave: Cooperativas de crédito. Eficiencia. Riesgo de crédito. DEA. Tobit. 


\section{INTRODUÇÃO}

As cooperativas de crédito fornecem crédito e serviços financeiros a comunidades que, de outra forma, poderiam não ter acesso a eles, especialmente em tempos de crises econômicas (CREAR, 2009). Todavia, suas atividades estão sujeitas a riscos diversos. A ampliação da participação dessas organizações no Sistema Financeiro Nacional (SFN) pode impactar na competitividade do setor, o que poderia levar a uma maior tomada de risco por parte delas (FIORDELISI, MARQUES-IBANEZ e MOLYNEUX, 2011). Esses riscos, muitas vezes, culminaram em falência, como ocorreu com o banco americano Lehman Brothers, o Banco Nacional e o Banco do Comércio e da Indústria de São Paulo, evidenciando o cenário de elevado risco em que essas instituições se inserem (MELO e LIMA, 2015).

A preocupação com as situações de risco envolvendo instituições financeiras na década de 1970 levou ao surgimento do Comitê de Supervisão Bancária de Basileia (BCBS), que instituiu novos parâmetros de requerimento de capital regulamentar, considerando os riscos associados a exposições, governança e transparência das instituições financeiras (BANCO CENTRAL DO BRASIL, 2019a).

Entre os riscos atrelados às organizações financeiras, há o de crédito, o de liquidez, o operacional e o de mercado, de modo que o gerenciamento de riscos deve fazer parte das atividades das cooperativas de crédito, mesmo que tais organizações não tenham por finalidade a acumulação de lucros, e sim prestar serviços aos associados de forma eficiente. Uma gestão inadequada dos riscos pode impactar, de maneira decisiva, na continuidade das organizações, podendo levar uma cooperativa à dissolução (FREITAS, AMARAL e BRAGA, 2008; KAUPELYTÈ e MCKARTHY, 2006).

Um potencial efeito da crise econômica sobre o sistema financeiro é a elevação dos níveis de inadimplência e, por consequência, menores margens na atividade. $O$ volume de créditos inadimplentes se torna uma proxy para mensurar a estabilidade financeira porque há altos níveis de inadimplência em bancos insolventes (BERGER e DEYOUNG, 1997; PODPIERA e WEILL, 2008). Em diversas investigações, os créditos inadimplentes, ou mesmo as estimativas de perdas com eles, foram usados como proxies de risco para instituições financeiras (BRANCO, SALGADO, CAVA et al., 2017; CAVA, SALGADO, BRANCO et al., 2016; HOU, WANG e ZHANG, 2014; SATHYE, 2005; TABAK, CRAVEIRO e CAJUEIRO, 2010). A crise financeira iniciada por volta de 2008 realçou a necessidade de monitorar a "saúde" das instituições financeiras, e o aumento na tendência à inadimplência continua sendo um bom indicador de risco nos bancos, que ganhou muita atenção graças à associação de inadimplência com instabilidade financeira (SAEED e IZZELDIN, 2014). Tal fato está ligado ao risco de crédito, que pode ser descrito como a probabilidade de não cumprimento da promessa de pagamento realizada pelo tomador no momento da contratação, ou a perda financeira potencial resultante de inadimplência do empréstimo (HUSCHER, 2017; SATHYE, 2005). Assim, a decisão de concessão de crédito é considerada complexa, uma vez que envolve aspectos que vão além do perfil de risco do tomador e da operação, incluindo as políticas de crédito e os objetivos da organização, o que demanda alinhamento estratégico com a gestão (SILVA, 2014).

Neste estudo, o risco de crédito é definido como a possibilidade de ocorrência de perdas associadas ao não cumprimento, pela contraparte, de suas obrigações nos termos pactuados, como fundamentado na Resolução do CMN no 4.557 (BRASIL, 2017) - sendo esse risco, portanto, o foco de análise nesta pesquisa.

As medidas de eficiência têm sido utilizadas como medidas de desempenho, em especial no setor das instituições financeiras. A eficiência técnica é a capacidade de minimizar a relação entre insumos e produtos, objetivando assegurar a melhor utilização dos recursos da instituição (PEÑA, 2008). No caso das cooperativas de crédito, buscam-se maximizar os benefícios aos cooperados.

Diversos estudos relacionaram a eficiência e o risco em bancos (ALTUNBAS, CARBO, GARDENER et al., 2007; CARNEIRO, SALGADO JUNIOR e MACORIS, 2016; FIORDELISI, MARQUES-IBANEZ e MOLYNEUX, 2011; PASTOR e SERRANO, 2005; TAN e ANCHOR, 2017; TAN e FLOROS, 2018), mas pesquisas nessa temática relacionadas às cooperativas de crédito ainda são poucas e não necessariamente dizem respeito a risco e eficiência (FREITAS, AMARAL e BRAGA, 2008; FRANCISCO, AMARAL e BERTUCCI, 2012; HUSCHER, 2017).

Dada a relevância da análise de risco de crédito, destaca-se que as cooperativas têm na concessão de crédito a atividade mais relevante, que garante a continuidade de suas operações (HUSCHER, 2017). Nesse contexto, este estudo responderá à seguinte questão: qual é a relação entre o risco de crédito e a eficiência técnica das cooperativas brasileiras no período de 2008 a 2017 ? 
Trata-se de um tema atual, que tem impacto na sociedade, dada a atividade dessas empresas. Também tem efeitos na perspectiva das próprias cooperativas, subsidiando suas decisões estratégicas e, de forma adicional, contribuindo para as políticas de regulação dessas instituições, bem como para a academia, ao investigar um tema pouco investigado até o momento.

Constatou-se que o maior risco de crédito impacta em menor eficiência por parte das cooperativas de crédito brasileiras e que o cenário de instabilidade decorrente da retração da economia brasileira a partir de 2015 provocou uma redução da eficiência técnica delas, apesar de, no período de 2008 a 2017 terem alcançado, em média, um escore de eficiência técnica de 99,78\%.

\section{RISCOS E EFICIÊNCIA EM INSTITUIÇÕES FINANCEIRAS}

As cooperativas de crédito estão expostas aos mesmos riscos que os bancos no que tange à intermediação financeira, sobretudo porque a atividade bancária é caracterizada como uma atividade tipicamente arriscada. As cooperativas, mesmo não tendo por finalidade acumulação de lucros, e sim prestar serviços aos seus associados, devem se ater à gestão eficiente dos riscos inerentes a sua atividade. A falta de controle sobre os riscos afeta diretamente o nível de segurança e de garantias sobre as operações realizadas, levando-as a se afastar de sua finalidade principal, que é garantir eficiência na prestação de seus serviços (FREITAS, AMARAL e BRAGA, 2008; PEREIRA, 2006).

A gestão de riscos é de singular importância para a sobrevivência e a solidez dos sistemas financeiros. Por esse motivo, constitui um dos principais focos de preocupação tanto das próprias instituições quanto da supervisão bancária mundial, conforme destacam Stiglitz (1994) e Jorion (2003).

Kaupelytè e McCarthy (2006) realçam que, em alguns casos, o gerenciamento inadequado dos riscos pode levar à liquidação de cooperativas de crédito singulares ou, inclusive, de toda a rede de cooperativas. A administração dos riscos em tais instituições muitas vezes está relacionada aos estágios de desenvolvimento das cooperativas. Na medida em que se desenvolvem, o profissionalismo e os altos padrões de gerenciamento de riscos devem se aprimorar junto com a expansão de serviços e atividades. Isso, em geral, acarreta um aumento na regulamentação das atividades das cooperativas de crédito.

A Resolução do CMN no 4.557 (BRASIL, 2017) regulamenta que as instituições financeiras devem manter uma estrutura de gerenciamento contínuo e integrado de riscos compatível com o modelo de negócio, com a natureza das operações e com a complexidade dos produtos, dos serviços, das atividades e dos processos da instituição.

As instituições financeiras estão sujeitas a muitos tipos diferentes de riscos, mas o de crédito é o mais significativo para a maior parte delas, sendo, portanto, o foco do Acordo de Basileia (1988).

O risco de crédito é definido, de acordo com a Resolução no 4.557 (BRASIL, 2017), do Conselho Monetário Nacional (CMN), como a possibilidade de ocorrência de perdas associadas a: (i) não cumprimento pela contraparte de suas obrigações nos termos pactuados; (ii) desvalorização, redução de remunerações e ganhos esperados em instrumento financeiro decorrentes da deterioração da qualidade creditícia da contraparte, do interveniente ou do instrumento mitigador; (iii) reestruturação de instrumentos financeiros; ou (iv) custos de recuperação de exposições caracterizadas como ativos problemáticos, nos termos do art. 24.

O risco de crédito está ligado à probabilidade de não cumprimento da promessa de pagamento realizada pelo tomador no momento da contratação ou à potencial perda financeira resultante de inadimplência do empréstimo (HUSCHER, 2017; SATHYE, 2005). Esse tipo de risco tem sido mais relacionado a problemas de falências bancárias, sendo também um dos mais comuns, já que a atividade de organizações como bancos e cooperativas de crédito consiste na concessão de empréstimos (STUCHI, 2004).

A Resolução do CMN no 2682 (BRASIL, 1999) dispõe que as instituições financeiras e demais empresas autorizadas a funcionar pelo Banco Central do Brasil (BACEN) devem classificar as operações de crédito, em ordem crescente de risco, nos seguintes níveis: $A A, A, B, C, D, E, F, G$ e H. Tal classificação é de responsabilidade da instituição detentora do crédito e deve ser efetuada com base em critérios consistentes e verificáveis.

Melo e Lima (2015) destacam que os problemas ocorridos em instituições financeiras ao redor do mundo culminaram, em muitos casos, na falência dessas organizações e evidenciaram o cenário de elevado risco em que se inserem. Assim, Freitas, Amaral e Braga (2008) salientam a importância da gestão de riscos nas cooperativas de crédito. 
Vários estudos abordam o risco de crédito nas instituições financeiras. Em âmbito internacional, Salas e Saurina (2002) compararam os determinantes de empréstimos problemáticos de bancos comerciais e de poupança espanhóis no período de 1985 a 1997, levando em consideração variáveis macroeconômicas e de nível bancário individual. Os autores constataram que a taxa de crescimento do Produto Interno Bruto (PIB), o endividamento familiar, a rápida expansão do crédito ou das agências, a ineficiência, a composição da carteira, o tamanho, a margem financeira, o índice de capital e o poder de mercado são variáveis que explicam o risco de crédito. Eles também ressaltam que existem diferenças significativas entre bancos comerciais e de poupança, confirmando a relevância da forma institucional na gestão do risco de crédito.

Sathye (2005) examinou os efeitos da introdução das transações da ferramenta de internet banking no desempenho e no perfil de risco das cooperativas de crédito australianas, concluindo que essa adoção não alterou o perfil de risco das cooperativas. Hackbarth, Miao e Morellec (2006) desenvolveram uma estrutura para analisar o impacto das condições macroeconômicas no risco de crédito e na escolha dinâmica da estrutura de capital. Inicialmente, eles observaram que, quando os fluxos de caixa dependem das condições econômicas atuais, há um benefício para as empresas adaptarem suas políticas de inadimplência e financiamento à posição da economia na fase do ciclo de negócios.

Marcucci e Quagliariello (2009) investigaram a relação entre risco de crédito e o ciclo dos negócios, tanto no nível agregado quanto no do banco, explorando um conjunto de dados exclusivo sobre as taxas de inadimplência dos tomadores de empréstimos dos bancos italianos. Os autores descobriram que os efeitos do ciclo de negócios sobre o risco de crédito são mais evidentes durante as desacelerações, bem como a ciclicidade também é maior para os bancos com carteiras mais arriscadas.

Imbierowicz e Rauch (2014) investigaram a relação entre risco de liquidez e de crédito. Eles utilizaram na análise os bancos comerciais dos Estados Unidos durante o período de 1998 a 2010 para analisar a relação entre essas duas fontes de risco no nível institucional do banco e como essa relação influencia as probabilidades de inadimplência. Os resultados mostraram que ambas as categorias de risco não tinham uma relação recíproca economicamente significativa, contemporânea ou com defasagem temporal. No entanto, influenciavam a probabilidade de inadimplência dos bancos.

Mais recentemente, Musau, Muathe e Mwangi (2018) analisaram o efeito da inclusão financeira no risco de crédito e o efeito de mediação da competitividade dos bancos comerciais no Quênia. O estudo concluiu que a disponibilidade, a acessibilidade e o uso dos bancos tiveram efeito significativo sobre o risco de crédito. A competitividade do banco foi encontrada para mediar parcialmente a relação entre inclusão financeira e risco de crédito.

No cenário nacional, as pesquisas de Costa (2005); Dantas, Rodrigues, Rodrigues et al. (2010); Francisco, Amaral e Bertucci (2012); Freitas, Amaral e Braga (2008); Huscher (2017) e Lima, Fonseca, Silveira et al. (2018) são exemplos de trabalhos que trataram sobre esse assunto.

Costa (2005) teve por objetivo criar um modelo de rating corporativo específico para as cooperativas agropecuárias, baseado na análise da bibliografia sobre risco de crédito. Freitas, Amaral e Braga (2008) analisaram os impactos do processo de conversão de uma cooperativa de crédito rural em cooperativa de crédito de livre admissão, caracterizando os riscos de liquidez e de crédito e a influência deles na sustentabilidade financeira dessa cooperativa. Como resultado, encontraram que a cooperativa estudada não deu a devida importância a gestão e análise dos riscos.

Numa investigação nas instituições financeiras brasileiras, Dantas, Rodrigues, Rodrigues et al. (2010) tiveram por objetivo avaliar o grau de transparência do risco de crédito praticado, tendo por referência as divulgações qualitativas e quantitativas requeridas pelo Acordo de Basileia II. Os autores perceberam que o grau de evidenciação apresentou crescimento paulatino e constante no período de 2001 a 2008, mas ainda atende a menos de $40 \%$ dos itens requeridos. Já Francisco, Amaral e Bertucci (2012) buscaram analisar, no âmbito das cooperativas de crédito, aquelas que geram maior risco de inadimplência, com base no perfil do cooperado, bem como quais estratégias poderiam ser apontadas para evitar possíveis falhas nas próximas análises. Assim, concluiu-se que as variáveis mais relevantes para identificar o risco de inadimplência foram a renda mensal bruta e o valor liberado na concessão de crédito.

Huscher (2017) buscou desenvolver um modelo de rating de crédito para avaliação de cooperativas. Por meio de uma regressão logística multinomial, foi possível desenvolver um modelo com quatro classificações: A (baixo), B (baixo médio), C (médio) e D (alto), com um poder preditivo geral de $80,1 \%$ - o pior risco (D), de $90,9 \%$, e o melhor (A), de $89,9 \%$, servindo como ferramenta a ser utilizada por instituições financeiras para análise de risco de cooperativas de crédito. Além disso, Lima, Fonseca, Silveira et al. (2018) tinham o objetivo de identificar os determinantes das classificações de crédito em bancos brasileiros de capital 
aberto no período de 2006 a 2015. Em suma, os achados evidenciaram que variáveis relativas a desempenho, liquidez, adequabilidade/qualidade do ativo e tamanho tiveram impacto estatisticamente significativo no nível de rating dos bancos. Verificou-se ainda uma piora dos ratings de crédito, a qual pôde ser atrelada à retração da economia, observada no Brasil durante o período de análise do estudo.

Fundamentando-se nos parâmetros trazidos pelo Comitê de Basileia e no próprio entendimento de que o risco de crédito está ligado à probabilidade de não cumprimento da promessa de pagamento realizada pelo tomador, no momento da contratação, ou à perda financeira potencial resultante de inadimplência do empréstimo, muitos trabalhos (AKWAA-SEKYI, KOFI e GENÉ, 2017; ANNIBAL, 2009; CHANG e CHIU, 2006; CHAIBI e FTITI, 2015; CUCINELLI, DI BATTISTA, MARCHESI et al., 2018; FERREIRA, OLIVEIRA, SANTOS et al., 2011; FIORDELISI, MARQUES-IBANEZ e MOLYNEUX, 2011; FRANCISCO, AMARAL e BERTUCCI, 2012; MUSAU, MUATHE e MWANGI, 2018; SALAS e SAURINA, 2002; TABAK, CRAVEIRO e CAJUEIRO, 2010) adotaram as variáveis "inadimplência" e "perda estimada com créditos de liquidação duvidosa" como representações do risco de crédito.

Annibal (2009) lembra, que embora uma instituição financeira possa não saber previamente as perdas a que estará submetida em determinado período, pode, dada a sua experiência, estimar um nível de perda para o período. Pastor e Serrano (2005) consideraram a provisão para perdas com créditos duvidosos como proxy do risco de crédito na suposição de que quanto maior fosse o volume de maus empréstimos, maior seria a provisão correspondente. Na mesma direção, Pastor (2002) argumentou que, nas provisões para perdas com empréstimos, a empresa considera implicitamente o risco associado a cada empréstimo problemático.

Sobre a inadimplência, Cucinelli, Di Battista, Marchesi et al. (2018) descrevem que essa é uma medida amplamente utilizada em outros estudos relevantes para representar o risco de crédito acumulado de uma instituição, sendo considerada a materialização desse risco, conforme considerado por Fiordelisi, Marques-Ibanez e Molyneux (2011). Assim, Chang e Chiu (2006) também reforçaram que muitos estudos apontaram que tanto a inadimplência quanto a perda estimada para créditos duvidosos são indicativos do risco de crédito, conforme adotado na presente pesquisa.

Entre as diversas classes possíveis para medir o desempenho, têm-se as medidas contábeis-financeiras, de clientes ou de mercado, de inovação e aprendizado, sociais, ambientais, comportamentais/situacionais, agregadas ou gerais e as de processos internos - as últimas incluem as análises de eficiência, que sinalizam quão bem os recursos vêm sendo usados para gerar receitas e indicam a existência de desperdício de recursos. A análise de desempenho engloba avaliações de informações de cunho financeiro e aspectos não financeiros. Deve-se considerar que o setor cooperativista é composto por um tipo organizacional peculiar, que pode atuar como fomentador no desenvolvimento social e, ao mesmo tempo, deve se manter viável economicamente ao ser competitivo com as demais organizações, além de ter de lidar com as expectativas de seus associados, sinalizando a aderência da análise de eficiência em termos de desempenho, no contexto dessas instituições.

Em âmbito internacional, alguns trabalhos investigaram a relação entre o risco e a eficiência. Pastor e Serrano (2005) analisaram a eficiência e o risco de crédito dos bancos dos países mais importantes da área do euro e constataram que os ajustes de risco são importantes no caso de eficiência de lucro, mas não no de eficiência de custo. Altunbas, Carbo, Gardener et al. (2007) analisaram a relação entre capital, risco e eficiência para uma amostra de bancos europeus entre 1992 e 2000 . Os autores não encontraram uma relação positiva entre ineficiência e risco bancário. No caso dos bancos cooperativos, encontraram que os níveis de capital estavam inversamente relacionados aos riscos e que bancos ineficientes detinham níveis mais baixos de capital.

Fiordelisi, Marques-Ibanez e Molyneux (2011) também avaliaram a relação entre eficiência, capital e risco de bancos comerciais europeus. As conclusões apontaram que a menor eficiência bancária, em relação a custos e receitas, causa maior risco bancário, e que aumentos no capital bancário precedem as melhorias na eficiência de custos. Os resultados indicaram que bancos mais eficientes acabam se tornando mais capitalizados, bem como que níveis mais altos de capital tendem a ter um efeito positivo nos níveis de eficiência. Os autores ressaltam que tais achados têm implicações importantes para a supervisão prudencial dos bancos e destacam a importância de obter ganhos de eficiência de longo prazo para apoiar os objetivos de estabilidade financeira.

Sarmiento e Galán (2017) mostraram evidências sobre a influência do risco na eficiência bancária em mercados emergentes e identificaram heterogeneidade na forma como o risco afeta os bancos com características diferentes. Os efeitos dos riscos na eficiência variam com tamanho e afiliação. Outro resultado do estudo foi que os bancos grandes e estrangeiros se beneficiavam mais da maior exposição aos riscos de crédito e de mercado, enquanto os domésticos e pequenos eram mais capitalizados. Tan e Floros (2018) testaram as inter-relações entre risco, concorrência e eficiência no setor bancário chinês entre 2003 e 2013. As relações encontradas foram que os bancos comerciais chineses com maior eficiência apresentaram maior risco de crédito e de insolvência, porém menor risco de liquidez e de capital. 
Referindo-se à literatura nacional, o trabalho de Tabak, Craveiro e Cajueiro (2010) buscou identificar a relação de causalidade entre créditos inadimplentes e eficiência bancária nas instituições brasileiras. Os autores encontraram que um aumento no nível de crédito inadimplente pode ser explicado por uma diminuição da eficiência, provavelmente manifestada também em falhas no gerenciamento de avaliação de riscos. Carneiro, Salgado Junior e Macoris (2016) avaliaram o grau de eficiência de 99 instituições financeiras que atuaram, em 2013, no mercado financeiro brasileiro. Os autores identificaram 22 com maior grau de eficiência, havendo certa heterogeneidade em relação à origem do capital, ao porte e ao setor de atuação. Por outro lado, foi identificado um indício de que há uma relação diretamente proporcional positiva entre o rating de crédito e a eficiência das instituições analisadas.

De maneira similar, Cava, Salgado, Branco et al. (2016) avaliaram a eficiência de bancos que atuaram no mercado brasileiro em 2013. Os resultados indicaram que os grandes bancos têm a maior pontuação média, sugerindo que são mais eficientes. Os bancos públicos federais tiveram o maior escore de eficiência média, em comparação a outros bancos. Aqueles com capital e participação estrangeiros tiveram pontuações médias altas. Os que operam em moeda estrangeira apresentaram os melhores escores de eficiência média. Quanto à classificação de risco, os classificados como AAA apresentaram maiores escores de eficiência média, sugerindo que os bancos com melhores serviços têm resultados mais sólidos e melhor classificação.

Por meio do levantamento dos estudos relacionados à temática em questão, não se verificou, até o presente momento, nenhum trabalho que tenha tratado da relação entre eficiência e risco de maneira focada nas cooperativas de crédito brasileiras. Esta pesquisa contribuirá de forma a diminuir a lacuna existente na literatura nacional sobre o assunto.

A análise dos trabalhos já publicados sobre o tema, no Brasil e em outros países, permitiu a identificação prévia das variáveis para o modelo de análise de eficiência das cooperativas de crédito: depósitos totais, despesa com pessoal, despesa de captação, despesas administrativas e outras, como variáveis de input, além de operações de crédito e sobras como output. Conforme apresentado a seguir, as variáveis do modelo foram validadas e complementadas por especialistas.

\section{METODOLOGIA}

\section{Amostra}

Os dados semestrais contábeis referentes às cooperativas de crédito brasileiras foram obtidos na base de dados do Plano Contábil das Instituições Financeiras (Cosif), disponibilizados no site do Bacen. Trabalhou-se com o período de 2008 a 2017. A amostra final foi composta de 450 cooperativas singulares (46,5\%) que resultaram em 9 mil observações. As cooperativas excluídas da amostra foram as classificadas como capital e empréstimo - porque não realizam captação de depósitos -, bem como aquelas que apresentaram informações faltantes em algum período analisado. Portanto, utilizou-se um painel balanceado. Levantou-se também, no site do Bacen, nos relatórios de autorizações e alterações societárias das instituições financeiras, as cooperativas de crédito que realizaram incorporações e cisões.

Um questionário foi utilizado como instrumento nesta pesquisa. Inicialmente, realizou-se o pré-teste. Depois, esse instrumento de pesquisa foi enviado para especialistas em cooperativas de crédito, além de técnicos do Bacen. Esse instrumento teve como objetivo identificar os fatores considerados adequados para a avaliação da eficiência técnica das cooperativas de crédito, no intuito de verificar se as variáveis apontadas pela literatura representavam, de fato, a realidade das instituições analisadas, além da possibilidade de incorporar novas variáveis à análise.

Nessa etapa, a metodologia de amostragem utilizada foi do tipo "bola de neve", no qual inicialmente se localizam algumas pessoas com o perfil necessário à pesquisa. Assim, o questionário foi enviado para 42 indivíduos num primeiro momento, sendo que seus contatos foram obtidos de forma majoritária, junto a cadastros e indicações realizados em consultas ao Bacen. De forma subsequente, solicitou-se que os respondentes iniciais indicassem novos contatos com as características desejadas, de sua própria rede pessoal, e assim sucessivamente. Dessa forma, a amostra pode crescer a cada ciclo, sendo esse o interesse dos pesquisadores. Ao final dessa etapa, foi obtida a colaboração de 17 respondentes. Destaca-se a grande contribuição deles, a qual permitiu trazer variáveis essenciais à análise da eficiência técnica nas cooperativas brasileiras, promovendo a interação da experiência de profissionais e usuários dessas instituições ao trabalho acadêmico. A Tabela 1 apresenta o perfil dos respondentes. 
Tabela 1

Perfil dos respondentes

\begin{tabular}{lc}
\hline \multicolumn{1}{c}{ Área de atuação } & $\%$ \\
\hline Controladoria e finanças em cooperativas de crédito & 17,65 \\
\hline Gestor de cooperativas de crédito & 23,5 \\
\hline Gerente de cooperativas de crédito & 11,8 \\
\hline Profissionais vinculados ao Bacen & 11,76 \\
\hline Outros* & 35,29 \\
\hline Tempo de atuação em cooperativas de crédito & $\%$ \\
\hline Menos de 10 anos & 18 \\
\hline 10 a 20 anos & 41 \\
\hline Mais de 20 anos & 18 \\
\hline Não atuam em cooperativas de crédito ou não & 23 \\
\hline responderam & $\%$ \\
\hline \multicolumn{1}{c}{ É cooperado em cooperativa de crédito } & 76,5 \\
\hline Sim & 23,5 \\
\hline Não & $\%$ \\
\hline Sul & 29,4 \\
\hline Nudentro respondeu & 23,5 \\
\hline
\end{tabular}

Nota: *Inclui profissionais de outras instituições financeiras, especialistas de mercado e do Fundo Garantidor do Cooperativismo de Crédito.

Fonte: Resultados da pesquisa.

\section{MODELO ANALÍTICO}

\section{Data Envelopment Analysis}

A eficiência técnica foi escolhida para mensurar o desempenho das cooperativas de crédito brasileiras neste estudo. As primeiras investigações acerca da temática remontam ao trabalho seminal de Charnes, Cooper e Rhodes (1978) e de Farrel (1957).

Data Envelopment Analysis (DEA) consiste numa técnica não paramétrica que usa um modelo de programação linear para avaliar a eficiência relativa de um conjunto de entidades homogêneas - Decision Making Units (DMUs) - conhecidas como tomadoras de decisão que utilizam os mesmos insumos e produzem saídas similares. Baseia-se no conceito de eficiência técnica proposto por Farrell (1957) e foi desenvolvido matematicamente por Charnes, Cooper e Rhodes (1978). O método identifica as DMUs que representam as melhores práticas por meio da comparação de cada DMU com todas as possíveis combinações lineares das demais unidades. O grupo de DMUs eficientes forma o limite eficiente e a distância radial do resto das entidades ao referido limite, identificando o comportamento ineficiente (CAMPILLO, SANTOS e FERNÁNDEZ, 2017).

Fundamentando-se em estudos anteriores no contexto das cooperativas de crédito, como Bittencourt, Bressan, Goulart et al. (2017); Bressan, Lopes e Menezes (2013); Souza, Braga e Ferreira (2011) este estudo utiliza um modelo com retornos variáveis à escala e com orientação a produto, proposto por Banker, Charnes e Cooper (1984), uma vez que objetiva avaliar a capacidade 
das cooperativas de crédito de fornecer o máximo rendimento possível aos seus membros e à sociedade, considerando os recursos disponíveis. $\mathrm{O}$ estimador é obtido resolvendo-se o seguinte problema de programação linear (Equação I), que deve ser resolvido $n$ vezes, um para cada DMU da amostra:

$$
\hat{\delta}=\max \hat{\delta}_{i \lambda}\left\{\delta>0 \mid \hat{\delta}_{i} y_{i} \leq \sum_{y=1}^{n} y_{i} \lambda ; x_{i} \geq \sum_{y=1}^{n} x_{i} \lambda ; \sum_{y=1}^{n} \lambda_{i}=1 ; \lambda \geq 0\right\} ; i=1 \ldots, n \text { DMUs (I) }
$$

em que $Y_{i}$ é o vetor de saída; $X i$ é o vetor de insumos; $\lambda$ é um vetor $\mathrm{n} \times 1$ de constantes que medem os pesos usados para calcular a localização de DMUs ineficientes para se tornarem eficientes; $\hat{\delta}_{i}$ é o índice de eficiência para a DMU i. Assim, se $\hat{\delta}_{i}=1$ a DMU i é eficiente e se $\hat{\delta}_{i}<1$ a DMU i é relativamente ineficiente.

Foi utilizado o modelo de DEA em dois estágios. No primeiro, os escores de eficiência foram estimados usando um modelo DEA convencional baseado num conjunto de variáveis de entrada e saída. Em seguida, as estimativas de eficiência DEA são regredidas, via modelo Tobit, com as variáveis explicativas. A Tabela 2 evidencia as variáveis efetivamente utilizadas no modelo de DEA, escolhidas conforme a literatura aplicável, bem como pela expertise e pela validação dos especialistas consultados por meio da ferramenta do questionário.

Tabela 2

Variáveis que compuseram o modelo DEA no primeiro estágio

\begin{tabular}{|c|c|c|c|}
\hline & Variáveis & Sigla & Códigos Cosif \\
\hline \multirow{9}{*}{  } & Depósitos totais & DT & [41000007] \\
\hline & Despesa de captação & DC & [81100008] \\
\hline & $\begin{array}{l}\text { Despesas de obrigações por empréstimos e } \\
\text { repasses }\end{array}$ & Doer & [81200001] \\
\hline & $\begin{array}{l}\text { Despesas com títulos e valores mobiliários } \\
\text { Instrumentos Financeiros Derivativos }\end{array}$ & DTVM & [81500000] \\
\hline & Despesas de participações & DPART & [81600003] \\
\hline & Aprovisionamentos e ajustes patrimoniais & DAP & [81800009] \\
\hline & Outras despesas operacionais & ODO & [81900002] \\
\hline & Despesas administrativas & DA & [81700006] \\
\hline & Despesa com pessoal & DP & $\begin{array}{c}{[81718005]+} \\
{[81727003]+} \\
{[81730007]+} \\
{[81733004]+} \\
{[81736001]+} \\
{[81737000]+} \\
{[81990201]}\end{array}$ \\
\hline \multirow{8}{*}{\begin{tabular}{l}
$n$ \\
\multirow{2}{5}{} \\
\multirow{2}{5}{} \\
0
\end{tabular}} & Operações de crédito & OC & [16000001] \\
\hline & Sobras & SO & [61700002] \\
\hline & Reservas & RS & $\begin{array}{c}{[61300000]} \\
+[61400003] \\
+[61500006]\end{array}$ \\
\hline & Rendas de operações de crédito & $\mathrm{ROC}$ & [71100001] \\
\hline & $\begin{array}{l}\text { Rendas de aplicações interfinanceiras de } \\
\text { liquidez }\end{array}$ & Rail & [71400000] \\
\hline & Rendas com títulos e valores mobiliários & RTVM & [71500003] \\
\hline & Rendas de prestação de serviços & RPS & [71700009] \\
\hline & Outras receitas operacionais & ORO & [71900005] \\
\hline
\end{tabular}

Fonte: Elaborada pelos autores. 


\section{Segundo estágio: modelo Tobit}

Levando-se em consideração a ampla quantidade de possíveis tratamentos estatísticos para realização das análises em segundo estágio de DEA, Hoff (2007) e Turner, Windle e Dresner (2004) consideram que o modelo de regressão Tobit é um método consistente, além de ser o mais utilizado por pesquisadores na área de instituições financeiras (AMOAH, OHENE-ASARE e ABOAGYE, 2018; BRESSAN, LOPES e MENEZES, 2013; CAMPILLO, SANTOS e FERNÁNDEZ, 2017; KAR e DEB, 2018; STAUB, SOUZA e TABAK, 2010; SUN, SUN e RABARISON, 2018). A adequabilidade do modelo se refere a situações em que o regressando é constituído por uma amostra contínua e limitada, como ocorre com os escores de eficiência calculados por DEA, uma vez que esses valores correspondem ao intervalo contínuo definido em [0;1], assumindo probabilidade positiva para o valor 1 (HOFF, 2007).

\section{Variáveis e especificação do modelo Tobit: risco de crédito (RCINAD; RCPECLD)}

A relação entre risco de crédito e eficiência não é conclusiva na literatura. Algumas pesquisas constataram que, quanto maior o risco de crédito, menor a eficiência da instituição (ALTUNBAS, CARBO, GARDENER et al., 2007; BRANCO, SALGADO, CAVA et al., 2017; TABAK, CRAVEIRO e CAJUEIRO, 2010). Por outro lado, Hou, Wang e Zhang (2014); Tan e Anchor (2017); Tan e Floros (2018) encontraram relação de quanto maior o risco de crédito, maior a eficiência da instituição. Neste estudo, espera-se que ocorra o mesmo comportamento dos bancos brasileiros (TABAK, CRAVEIRO e CAJUEIRO, 2010), ou seja, assume-se que as cooperativas com menor risco de crédito serão as de maior eficiência técnica. As variáveis do risco de crédito serão obtidas da seguinte maneira:

1. RCINAD: Esse indicador considerará inadimplente uma operação de crédito que tenha parcelas em atraso por mais de 90 dias (BANCO CENTRAL DO BRASIL, 2017; BASEL II, 2006; CUCINELLI, DI BATTISTA, MARCHESI et al., 2018; FIORDELISI, MARQUES-IBANEZ e MOLYNEUX, 2011; RELATÓRIO DE ESTABILIDADE FINANCEIRA, 2017) e será computado como na Equação II:

$$
\text { RCINAD }=\frac{\text { Total das operações inadimplentes }}{\text { Total das operações de crédito }} \text { (II) }
$$

2. RCPECLD: conforme a Resolução $n=2.682 / 2009$ do $C M N$, a provisão deve ser constituída mensalmente para fazer face aos créditos de liquidação duvidosa. A resolução determina que os percentuais de provisão variam do mínimo de $0,5 \%$ (nível A) até $100 \%$ (nível H). Assim, a variável RCPECLD utilizada como proxy para analisar o risco de crédito segue o direcionamento da resolução do CMN, que também foi adotada por outros autores (CHO e CHUNG CUCINELLI, 2016; CUCINELLI, DI BATTISTA, MARCHESI et al., 2018; SATHYE, 2005; TOLEDO, KROENKE e SOTHE, 2009) e obtida conforme Equação III.

$$
\text { RCPECLD }=\frac{\text { Perda estimada com créditos de liquidação duvidosa do período }}{\text { saldo das operações de crédito }} \text { (III) }
$$

3. Tamanho (LNAT): O tamanho é uma variável de controle e será medida por meio do logaritmo natural do ativo total. Para Andries, Cãpraru e Nistor (2018); Campillo e Santos (2016); Campillo, Santos e Fernández (2017), as instituições maiores tendem a apresentar maiores níveis de eficiência. Já a relação oposta foi encontrada por Cázares, Sáez e Marco (2013), bem como por Branco, Salgado, Cava et al. (2017). Assim, a relação entre a variável tamanho e a eficiência das cooperativas pode ser negativa ou positiva.

4. Diversificação (DIV): Para Sang (2017), a relação entre a diversificação na eficiência dos bancos permanece inconclusiva. Para Krakah e Ameyaw (2010), os serviços prestados por instituições financeiras fora de suas atividades tradicionais favorecem o desempenho dessas instituições. Já para Gischer e Juttner (2001), a prestação de serviços fora da atividade principal tem relação negativa com a performance, uma vez que o mercado desses serviços tende a ser mais competitivo em comparação com o mercado das atividades tradicionais. Para as cooperativas de crédito, Vieira (2016) indicou que a diversificação proporciona benefícios. Nesse cenário, tal variável poderá ter relação positiva ou negativa com a eficiência e será calculada segundo a Equação IV.

$$
\text { DIV }=\frac{\text { Rendas não decorrentes de operações de crédito }}{\text { Receitas operacionais }} \text { (IV) }
$$


5. Dummy de recessão (DumR): Campillo, Santos e Fernández (2017) concluíram que a situação de crise teve um impacto negativo na eficiência das cooperativas de crédito espanholas. Glass, McKillop, Quinn et al. (2014) ressaltam que as organizações financeiras devem ser mais eficientes, sobretudo em tempos de crise, uma vez que estão inseridas em ambientes competitivos. No Brasil, a recessão econômica iniciada em 2015 foi a maior retração econômica dos últimos 25 anos (INSTITUTO DE PESQUISA ECONÔMICA APLICADA - IPEA, 2015), influenciando negativamente o desempenho das cooperativas de crédito brasileiras (CORDEIRO, BRESSAN, LAMOUNIER et al., 2018). Assim, a dummy de recessão assume valor igual a 1 quando os dados se referem ao período de 2015 a 2017; caso contrário, seu valor é 0 .

6. Tempo de existência (TE): As capacidades das firmas são formadas pela experiência obtida ao longo do tempo (CÁZARES, SÁEZ e MARCO, 2013). Assim, espera-se que, quanto maior for o tempo de existência da cooperativa, maiores deverão ser suas experiências de mercado e gerenciais, tendo-se a expectativa de que tal variável seja positivamente relacionada à eficiência.

7. Pontos de atendimento (PA): Para Campillo, Santos e Fernández (2017), instituições com maior número de pontos de serviços seriam mais eficientes. Todavia, deve-se considerar que o comportamento das novas gerações, a entrada de novas tecnologias e as formas de as organizações se relacionarem com seus clientes vêm sendo alterados ao longo dos anos. No Brasil, enquanto os bancos reduziram o número de agências físicas em 2017, as cooperativas filiadas ao Sicoob registraram expansão de 5,7\% entre 2016 e 2017, com a criação de 165 novos pontos de atendimento, tornando-se a quinta maior rede de atendimento no Brasil (MOTTA, 2018). Apesar do potencial de ampliação de atendimento a cooperados, os novos pontos também podem aumentar os custos operacionais. Assim, o número de PA poderá ter relação positiva ou negativa com a eficiência.

8. Dummy de incorporação (DumINC): Vieira (2016) detectou que a incorporação afetou negativamente o desempenho das cooperativas de crédito. No Brasil, tem-se observado um movimento de incorporações/fusões por parte das cooperativas crédito, inclusive incentivado pelo próprio regulador, permitindo, assim, melhores condições de competitividade com o sistema bancário tradicional (BANCO CENTRAL DO BRASIL, 2015). Assumiu-se uma dummy com valor igual a 1 para as cooperativas que foram incorporadas; caso contrário, o valor é 0 .

9. Dummy de efeito regional (DumERNE, DumERNO, DumERCO): Vários estudos trataram da existência do chamado "efeito regional", que sugere que a eficiência das instituições varia de acordo com sua localização geográfica dentro de determinado país (CAMPILLO, SANTOS e FERNÁNDEZ, 2017; GLASS, MCKILLOP, QUINN et al., 2014; WORTHINGTON, 1999). dummy de efeito regional Sul; DumERNE = dummy de efeito regional Nordeste; DumERNO = dummy de efeito regional Norte; DumERCO = dummy de efeito regional Centro-Oeste. Trata-se, portanto, de uma variável binária de controle nesta pesquisa.

Assim, no segundo estágio de DEA, foram utilizados dois modelos de regressão com dados em painel estimados pelo modelo Tobit, conforme Equações V e VI.

$$
\begin{aligned}
& \mathrm{Y} *_{\mathrm{it}}=\beta_{0}+\beta_{1} \mathrm{RCINAD}_{\mathrm{it}}+\beta_{2} \mathrm{TAM} \beta_{3} \mathrm{DIV}_{\mathrm{it}}+\beta_{4} \mathrm{TE}_{\mathrm{it}}+\beta_{5} \mathrm{PA}_{\mathrm{it}}+\beta_{6} \mathrm{DumR}_{\mathrm{it}}+\beta_{7} \mathrm{DumINC}_{\mathrm{it}}+ \\
& \beta_{8} \text { DumERSUL }_{i t}+\beta_{9} \text { DumERNE }_{\text {it }}+\beta_{10} \text { DumERNO }_{\text {it }}+\beta_{11} \text { DumERCO }_{\text {it }}+\mathrm{u}_{\mathrm{it}}(\mathrm{V}) \\
& \mathrm{Y} *_{\mathrm{it}}=\beta_{0}+\beta_{1 \mathrm{it}} \mathrm{RCPECLD}+\beta_{2} \mathrm{TAM}+\beta_{3} \mathrm{DIV}_{\mathrm{it}}+\beta_{4} \mathrm{TE}_{\mathrm{it}}+\beta_{5} \mathrm{PA}_{\mathrm{it}}+\beta_{6} \mathrm{DumR}_{\mathrm{it}}+\beta_{7} \mathrm{DumINC}_{\text {it }}+ \\
& \beta_{8} \text { DumERSUL }_{i t}+\beta_{9} \text { DumERNE }_{i t}+\beta_{10} \text { DumERNO }_{i t}+\beta_{11} \text { DumERCO }_{\text {it }}+\mathrm{u}_{\mathrm{it}}(\mathrm{VI})
\end{aligned}
$$

Sendo:

$Y^{*}=$ Escores de eficiência técnica das cooperativas de crédito obtidos por meio da metodologia DEA;

$\beta_{0}=$ Intercepto do modelo;

$i=1, \ldots, N$ cooperativas de crédito brasileiras;

$t=1, \ldots, T$ semestres e se refere ao período de 2008-1 até 2017-2;

$\beta_{i j}$ são os coeficientes angulares estimados para cada variável independente, descritas anteriormente;

$\mathrm{u}_{i t}=\alpha_{i}+\varepsilon_{i t}$ é o termo de erro composto em que $\alpha_{i}$ é o efeito individual não observado e $\varepsilon_{i t}$ é o termo de erro aleatório. 


\section{Procedimentos adotados na estimação do modelo Tobit}

Para obtenção do modelo Tobit final foram adotados os seguintes procedimentos: testes de significância individual das variáveis explicativas e comparação entre modelos restritos e irrestritos por meio do LRtest. $O$ teste apontou que o modelo restrito era o mais indicado tanto no modelo para a proxy de risco RCINAD quanto para a proxy RCPECLD. Por fim, os modelos (V) e (VI) foram substituídos pelos modelos restritos (VII) e (VIII).

$$
\begin{aligned}
& \mathrm{Y} *_{\mathrm{it}}=\beta_{0}+\beta_{1} \mathrm{RCINAD}_{\mathrm{it}}+\beta_{3} \mathrm{DIV}_{\mathrm{it}}+\beta_{4} \mathrm{TE}_{\mathrm{it}}+\beta_{5} \mathrm{PA}_{\mathrm{it}}+\beta_{6} \mathrm{DumR}_{\mathrm{it}}+\mathrm{u}_{\mathrm{it}}(\mathrm{VII}) \\
& \mathrm{Y} *_{\mathrm{it}}=\beta_{0}+\beta_{1} \mathrm{RCPECLD}_{\mathrm{it}}+\beta_{3} \mathrm{DIV}_{\mathrm{it}}+\beta_{4} \mathrm{TE}_{\mathrm{it}}+\beta_{5} \mathrm{PA}_{\mathrm{it}}+\beta_{6} \mathrm{DumR}_{\mathrm{it}}+\mathrm{u}_{\mathrm{it}}(\mathrm{VIII})
\end{aligned}
$$

\section{ANÁLISE E DISCUSSÃO DOS RESULTADOS}

As cooperativas de crédito brasileiras pesquisadas no período de 2008 a 2017 tinham em média três pontos de atendimento e 14,38 anos de existência - a cooperativa mais nova com aproximadamente 1,5 ano de existência e a mais antiga, com 51 . As proxies de risco de crédito RCINAD e RCPECLD indicaram grandes diferenças entre as cooperativas. No entanto, de modo geral, as cooperativas pesquisadas apresentaram um escore médio de eficiência de 99,78\% (Tabela 3).

Tabela 3

Estatísticas descritivas das variáveis do segundo estágio de DEA

\begin{tabular}{lccccccc}
\hline & Y & PA & TE & DIV & RCINAD & RCPECLD & Ativo total \\
\hline Média & $99,78 \%$ & 3,0742 & 172,6449 & 0,3792 & 19033,389 & 19100,0537 & $1,7674 \mathrm{e}^{+11}$ \\
\hline Desvio padrão & 0.28994 & 4,4330 & 88,5206 & 0,1481 & 645914,233 & 662517,5571 & $4,2677 \mathrm{e}^{+11}$ \\
\hline Mínimo & $99,17 \%$ & 1 & 0,53 & 0,0019 & 0 & 0 & $6,757,22$ \\
\hline Máximo & $100 \%$ & 36 & 612 & 1 & $3,90 \mathrm{e}^{+7}$ & $3,80 \mathrm{e}^{+7}$ & $6,578 \mathrm{e}^{+12}$ \\
\hline CV & 0.2905 & 1,4420 & 0,5127 & 0,3906 & 33,936 & 34,6867 & 2,4148 \\
\hline
\end{tabular}

Notas: O tempo de existência (TE) foi considerado (em meses). CV = Coeficiente de variação. $Y=$ Escore de eficiência técnica. Fonte: Resultados da pesquisa.

Os testes LR e Wald indicaram que os modelos Tobit 1 e 2 foram globalmente válidos (Tabela 4). Em ambos, quanto maior o risco de crédito, menor a eficiência técnica das cooperativas de crédito brasileiras, resultado compatível ao esperado nesta pesquisa e que corrobora outros estudos, como Branco, Salgado, Cava et al. (2017), Carneiro, Salgado Junior e Macoris (2016), Cava, Salgado, Branco et al. (2016), Fiordelisi, Marques-Ibanez e Molyneux (2011), Hou, Wang e Zhang (2014), Sathye (2005) e Tabak, Craveiro e Cajueiro (2010). 
Tabela 4

Resultados das estimações do Modelo Tobit no segundo estágio de DEA

\begin{tabular}{|c|c|c|c|c|}
\hline Variáveis & Modelo 1 & Dy/Dx Modelo 1 & Modelo 2 & Dy/Dx Modelo 2 \\
\hline RCINAD & $-2,56 e^{-10 * * *}$ & $-1,11 \mathrm{e}^{-10 * * *}$ & & \\
\hline RCPECLD & & & $-2,73 e^{-10 * * *}$ & $-1,18 e^{-10 * * *}$ \\
\hline PA & $-0,0000496 * * *$ & $-0,0000216^{* * *}$ & $-0,0000499 * * *$ & $-0,0000217 * * *$ \\
\hline $\mathrm{TE}$ & $3,16 e^{-6 * * *}$ & $1,37 e^{-6 * * *}$ & $3,17 e^{-6 * * *}$ & $1,38 e^{-6 * * *}$ \\
\hline DIV & $0,0019144 * * *$ & $0,0008314 * * *$ & $0,0019193 * * *$ & $0,0008334^{* * *}$ \\
\hline DumR & $-0,0005983 * * *$ & $-0,0002599 * * *$ & $-0,0005983 * * *$ & $-0,0002598 * * *$ \\
\hline Constante & $0,9978937 * * *$ & & $0,9978913 * * *$ & \\
\hline Wald (chi) & $64,67 * * *$ & & $65,11^{* * *}$ & \\
\hline LR(Likelihood-ratio test of sigma) & $2008,4^{* * *}$ & & $2014,5 * * *$ & \\
\hline sigma_u & $0,0024161 * * *$ & & $0,0024201 * * *$ & \\
\hline sigma_e & $0,0032925 * * *$ & & $0,0032918^{* * *}$ & \\
\hline Rho & ,3500124 & & ,3508661 & \\
\hline № de observações & 9000 & & 9000 & \\
\hline № de Grupos & 450 & & 450 & \\
\hline
\end{tabular}

Notas: Estatisticamente significativo a $* 10 \% ; * * 5 \% ; * * * 1 \%$. Modelo 1: Inadimplência (RCINAD).

Modelo 2: Perda Estimada com Créditos de Liquidação Duvidosa do período (RCPECLD). Dy/Dx = Efeito Marginal.

Fonte: Resultados da pesquisa.

Essa relação negativa entre risco de crédito e eficiência pode indicar que os gerentes, avessos ao risco, tenderiam a aumentar os gastos operacionais destinados à avaliação e ao monitoramento dos empréstimos, numa tentativa de controlar o aumento na inadimplência, o que impactaria, de forma negativa, a medida de eficiência do banco. Por outro lado, teria um efeito positivo sobre a inadimplência nas carteiras de crédito, de modo a reduzi-la. Assim, gerentes avessos ao risco tenderiam a elevar os gastos com monitoramento para ter controle dos créditos inadimplentes, o que reduziria a eficiência bancária (TABAK, CRAVEIRO e CAJUEIRO, 2010).

Outra justificativa seria o fato de o risco de crédito enfrentado pelas cooperativas ser causado sobremaneira por componentes exógenos, como as retrações econômicas. Em decorrência disso, as instituições incorreriam em custos maiores para monitorar o aumento na inadimplência, reduzindo, da mesma forma, a eficiência. Essa queda de eficiência técnica pode ter outra relação de causalidade e ser provocada por um desempenho insatisfatório dos gestores, que poderiam não monitorar corretamente a carteira de créditos, afetando a qualidade dos empréstimos e gerando alta inadimplência, a qual acarretaria perdas à cooperativa e potencializaria uma diminuição em seus indicadores de eficiência (BERGER e DEYOUNG, 1997).

Constatou-se que, quanto maior o número de pontos de atendimento, menores os escores de eficiência (Tabela 4). $\mathrm{O}$ aumento de pontos de atendimento pode ampliar os custos operacionais e, consequentemente, dificultar uma melhora da eficiência da instituição. Todavia, trata-se de uma decisão estratégica que precisa levar em consideração o bem-estar dos cooperados e seus interesses. Nesse caso, de modo semelhante, a dummy de recessão apresentou o comportamento de impactar de forma negativa a eficiência técnica das cooperativas de crédito brasileiras. Apesar de essas instituições terem mantido valores patrimoniais estáveis ou em crescimento no durante a crise financeira nacional, o período de recessão econômica impactou negativamente os indicadores de desempenho relativos à eficiência, corroborando com Cordeiro, Bressan, Lamounier et al. (2018), que evidenciaram que a recessão econômica iniciada em 2015 no Brasil influenciou o desempenho das cooperativas de crédito.

O tempo de existência da cooperativa e a diversificação de produtos financeiros impactaram de maneira positiva na eficiência das cooperativas. De acordo com os modelos estimados, uma instituição mais experiente, com mais tempo de atividade no mercado, pode aumentar seu escore de eficiência em comparação com uma mais nova. As experiências adquiridas pelo conhecimento de mercado, bem como as expertises em relação ao próprio funcionamento, podem contribuir para que tais 
cooperativas tenham os melhores resultados em termos de maximizar seus benefícios, despendendo o menor volume possível de recursos para suas atividades e decisões estratégicas.

Ainda nessa orientação, a diversificação tem se mostrado uma prática estratégica no âmbito das instituições cooperativas. Quanto mais diversificada, melhores tendem a ser os escores de eficiência, ou seja, um aumento na diversificação representa também um aumento na eficiência cooperativa, corroborando com os achados de Sathye (2005) e Sang (2017), que também obtiveram relação positiva entre a diversificação e a eficiência técnica.

Observou-se, pela análise dos coeficientes (Tabela 4), que algumas variáveis exógenas, como DIV e PA, foram mais impactantes na eficiência do que o próprio risco de crédito, apesar de todos terem se comportado de maneira significativa em termos estatísticos. Trata-se de variáveis que se relacionam mais intimamente com as contas de despesas e receitas das instituições, o que poderia contribuir para que esse impacto ocorra de forma mais acentuada nos escores de eficiência, em detrimento das próprias proxies de risco, que têm certa medida de incerteza em suas estruturas, comprometendo em menor grau a eficiência técnica. Outrossim, as carteiras de crédito das cooperativas vêm sendo constituídas essencialmente por créditos com melhores classificações de risco. Observou-se, no período de 2013 a 2017, que a carteira das instituições singulares permaneceu classificada majoritariamente em níveis de risco $A$ e $B$, o que também justificaria o menor impacto do risco de crédito na eficiência das cooperativas financeiras (BANCO CENTRAL DO BRASIL, 2019b).

Os efeitos marginais encontrados foram semelhantes nos dois modelos, não apresentando variações significativas em ambas as estimativas. Mesmo tendo apresentado valores pequenos, em termos percentuais, são estatisticamente relevantes e sinalizam o impacto de suas respectivas variáveis na eficiência técnica das cooperativas.

\section{CONSIDERAÇÕES FINAIS}

Uma gestão de riscos adequada e a manutenção de um desempenho satisfatório são fatores importantes para a continuidade de qualquer instituição, não sendo diferente para as cooperativas de crédito.

Este estudo analisou a relação entre o risco de crédito e a eficiência das cooperativas brasileiras. Fez uso da metodologia DEA em dois estágios para estimar os escores de eficiência de 450 instituições nacionais. Os achados do primeiro estágio de DEA apontaram que a média das eficiências em todo o período foi de $99,78 \%$ para as cooperativas analisadas. Foram consultados especialistas para a construção e a validação dos escores de eficiência, o que é uma contribuição deste estudo em relação aos demais.

No segundo estágio de DEA, por meio do Tobit, os modelos indicaram uma relação negativa e significativa entre o risco de crédito, medidos por RCINAD e RCPECLD, e a eficiência técnica das cooperativas financeiras, em concordância com os resultados de Tabak, Craveiro e Cajueiro (2010) para os bancos brasileiros. Esse resultado pode ser explicado pelo fato de os gestores passarem a ter um comportamento avesso ao risco e tenderem a aumentar os gastos operacionais destinados à avaliação e ao monitoramento dos empréstimos, numa tentativa de controlar o aumento da inadimplência, o que impacta de forma negativa a eficiência da cooperativa.

As variáveis pontos de atendimento e dummy de recessão também apresentaram relação estatisticamente significativa e negativa com a eficiência, denotando que, a despeito de redes de atendimentos maiores terem o potencial de atender a um maior número de usuários, podem aumentar os custos operacionais e se tornar inviáveis em termos de eficiência. Uma alternativa, nesse caso, seria o investimento em tecnologias de informação, criando-se a possibilidade de utilização de aplicativos de internet banking e de atendimentos on-line, mas sempre levando em consideração o interesse e o bem-estar dos cooperados. Além disso, no período de retração econômica brasileira entre 2015 e 2017, as cooperativas de crédito não se mostraram imunes, pois a dummy de recessão indicou o impacto negativo nos escores de eficiência médios.

De igual modo, a experiência adquirida pela cooperativa, medida por seu tempo de existência e pela diversificação de produtos financeiros, apresentou impactos positivos nos escores de eficiência, o que sinaliza que as cooperativas de crédito que conseguem manter a continuidade no mercado e diversificam seus produtos otimizam recursos e, consequentemente, geram mais benefícios aos seus associados. 
Sugere-se, para pesquisas futuras, avaliar o perfil dos gestores quanto à aversão ou não ao risco de crédito nas cooperativas, assim como discutir, na perspectiva desses gestores, os principais fatores motivadores do risco de crédito nas cooperativas e como as regulamentações do Conselho Monetário Nacional (CMN) impactam essa minimização do risco e o aumento ou não dos custos regulatórios, relacionando essas questões à eficiência técnica das cooperativas de crédito brasileiras. Em termos técnicos, também se sugere a consideração da análise de metafronteira de Malmquist, juntamente com a regressão bootstrap, para a inferência estatística dos estimadores de eficiência, já que em alguns casos os resultados encontrados por meio da estimação tradicional de DEA podem ser impactados pelo viés amostral e tenderiam a divergir dos que seriam encontrados caso se utilizasse a verdadeira fronteira de produção. Nesse caso, a técnica de bootstrap permite dar suporte à identificação de tais problemas e filtrar as informações relevantes nos resultados (AZAD, MUNISAMY, MASUM et al., 2017; BARROS e TENORIO JUNIOR, 2020).

\section{AGRADECIMENTOS}

Os autores agradecem a CAPES pelo financiamento desta pesquisa. 


\section{REFERÊNCIAS}

AKWAA-SEKYI, E. K.; GENÉ, M. J. Internal controls and credit risk relationship among banks in Europe. Intangible Capital, v. 13, n. 1, p. 25-50, 2017.

ALTUNBAS, Y. et al. Examining the relationships between capital, risk and efficiency in European banking. European Financial Management, v. 13, n. 1, p. 49-70, 2007.

AMOAH, B. et al. Technical efficiency: the pathway to credit union cost efficiency in Ghana. Managerial Finance, v. 44, n. 11, p. 1292 1310, 2018.

ANDRIEȘ, A. M.; CĂPRARU, B.; NISTOR, S. Corporate governance and efficiency in banking: evidence from emerging economies. Applied Economics, v. 50, n. 34-35, p. 3812-3832, 2018.

ANNIBAL, C. A. (2009). Inadimplência do setor bancário brasileiro: uma avaliação de suas medidas (Working Papers Series, 192). Brasília, DF: Banco Central do Brasil. Disponível em: <https://ideas.repec. org/p/bcb/wpaper/192.html>. Acesso em: 18 nov. 2020.

AZAD, M. A. K. et al. Bank efficiency in Malaysia: a use of malmquist meta-frontier analysis. Eurasian Bus Ver, v. 7, n. 2, p. 287-311, 2017.

BANCO CENTRAL DO BRASIL. Plano de Ação para Fortalecimento do Ambiente Institucional: Relatório 2012-2014. Parceria Nacional para Inclusão Financeira. Brasília, DF: Banco Central do Brasil, 2015. Disponível em: <http://www.bcb.gov.br/pec/appron/apres/Relat\%F3rio\%20 PNIF\%20\%20Br.\%200462.pdf>. Acesso em: 18 nov. 2020.

BANCO CENTRAL DO BRASIL. Relatório de Estabilidade Financeira. Brasília, DF: Banco Central do Brasil, 2017. Disponível em: <https:// www.bcb.gov.br/htms/estabilidade/2017_10/refPub.pdf>. Acesso em: 18 nov. 2020.

BANCO CENTRAL DO BRASIL. Novo Acordo de Capitais - Basileia II. Brasília, DF: Banco Central do Brasil, 2019a. Disponível em: <https://www.bb.com.br/portalbb/ page $51,136,3442,0,0,1,8 . b b$ ?codigoNoticia $=4813 \&$ codigoMenu $=413 \&$ codigoRet=4119\&bread=9_1_4>. Acesso em: 18 nov. 2020.

BANCO CENTRAL DO BRASIL. Panorama do sistema nacional de crédito cooperativo. Brasília, DF: Banco Central do Brasil, 2019b. Disponível em: <https://www.bcb.gov.br/pre/microFinancas/coopcar/ pdf/panorama_de_cooperativas2017.pdf>. Acesso em: 18 nov. 2020.

BANKER, R. D.; CHARNES, A.; COOPER, W. W. Some models for estimating technical and scale inefficiencies in DEA. Management Science, v. 30, n. 9, p. 1078-1092, 1984.

BARROS, E. S.; TENORIO JUNIOR, A. J. A. Aplicação do método Bootstrap na estimação de fronteiras não paramétricas: o caso dos fruticultores do vale do São Francisco. Fortaleza: Banco do Nordeste, 2020. Disponível em: <https://www.bnb.gov.br/documents/160445/214098/ aplicacao_do_metodo.pdf/4849e96f-e713-404a-b73f-4aa88b9e4cfd>. Acesso em: 18 nov. 2020.

BASEL CAPITAL ACCORD. International Convergence of Capital Measurement and Capital Standards (July 1988, Updated to April 1998). Basileia: Bank for International Settlements, 1988. Disponível em <http://www.bis.org/publ/bcbsc111.pdf>. Acesso em: 18 nov. 2020

BASEL II. International Convergence of Capital Measurement and Capital Standards: a revised framework, comprehensive version.
Basileia: Bank for International Settlements, 2006. Disponível em: <https://www.bis.org/publ/bcbs128.pdf>. Acesso em: 18 nov. 2020.

BERGER, A. N.; DEYOUNG, R. Problem loans and cost efficiency in commercial banks. Journal of Banking \& Finance, v. 21, n. 6, p. 849870, 1997.

BITTENCOURT, W. R. et al. Rentabilidade em bancos múltiplos e cooperativas de crédito brasileiros. Revista de Administração Contemporânea, v. 21, n. esp., p. 22-40, 2017.

BRANCO, A. M. F. et al. Efficiency of the Brazilian Banking System in 2014: A DEA-SBM Analysis. Journal of Applied Finance and Banking, v. 7, n. 5, p. 29-47, 2017.

BRASIL. Resolução no 2682, de 21 de dezembro de 1999. Dispõe sobre critérios de classificação das operações de crédito e regras para constituição de provisão para créditos de liquidação duvidosa. Brasília, DF: Diário da União, 1999. Disponível em: <http://www.bcb. gov.br/pre/normativos/res/1999/pdf/res_2682_v2_L.pdf>. Acesso em: 18 nov. 2020.

BRASIL. Resolução $n^{\circ} \mathbf{4 . 5 5 7}$, de 23 de fevereiro de 2017. Dispõe sobre a estrutura de gerenciamento de riscos e a estrutura de gerenciamento de capital. Brasília, DF: Diário da União, 2017. Disponível em: <http://www.bcb.gov.br/pre/normativos/busca/downloadNormativo. asp?arquivo=/Lists/Normativos/Attachments/50344/Res_4557_v1_O. pdf>. Acesso em: 18 nov. 2020.

BRESSAN, V. G. F.; LOPES, A. L. M.; MENEZES, M. R. Análise de eficiência das cooperativas de crédito brasileiras utilizando informações contábeis. In: CONGRESSO INTEGRADO DE CONTABILIDADE, 1., 2013, Juiz de Fora. Anais... Juiz de Fora: UFJF, 2013. Disponível em: <http://www. uff.br/congreconti/files/2013/11/A9.pdf>. Acesso em: 18 nov. 2020.

CAMPILLO, A. M.; SANTOS, Y. F. What about the Social efficiency in credit cooperatives? evidence from Spain (2008-2014). Social Indicators Research, v. 131, n. 2, p. 607-6299, 2016.

CAMPILLO, A. M.; SANTOS, Y. F.; FERNÁNDEZ, M. D. P. F. Eficiencia técnica en las cooperativas de crédito españolas: una aproximación al impacto de la crisis. Revista Española de Financiación y Contabilidad, v. 46, n. 4, p. 484-506, 2017.

CARNEIRO, M.; SALGADO JUNIOR, P. A.; MACORIS, L. S. Avaliação da eficiência bancária por meio da abordagem de intermediação: uma análise comparativa de instituições financeiras brasileiras. Revista Eletrônica de Administração, v. 22, n. 3, 336-359, 2016.

CAVA, P. B. et al. Evaluation of Bank Efficiency in Brazil: A Dea Approach. Revista de Administração Mackenzie, v. 17, n. 4, p. 62-84, 2016.

CÁZARES, C. C.; SÁEZ, C. B.; MARCO, T. G. You can't manage right what you can't measure well: Technological innovation efficiency. Research Policy, v. 42, n. 6-7, p. 1239-1250, 2013

CHAIBI, H.; FTITI, Z. Credit risk determinants: evidence from a crosscountry study. Research in International Business and Finance, v. 33, p. 1-16, jan. 2015.

CHANG, T. C.; CHIU, Y. H. Affecting factors on risk-adjusted efficiency in Taiwan's banking industry. Contemporary Economic Policy, v. 24, n. 4, p. 634-648, 2006. 
CHARNES, A.; COOPER, W. W.; RHODES, E. Measuring the efficiency of decision makingunits. European Journal of Operational Research, v. 2, n. 6, p. 429-444, nov. 1978.

CHO, M.; CHUNG, K. H. The effect of commercial banks' internal control weaknesses on loan loss reserves and provisions. Journal of Contemporary Accounting \& Economics, v. 12, n. 1, p. 61-72, 2016.

CORDEIRO, F. A. et al. Desempenho financeiro das cooperativas de crédito brasileiras e a recessão econômica de 2015 no Brasil. In: CONGRESSO USP INTERNATIONAL CONFERENCE IN ACCOUNTING, 2018, São Paulo. Anais... São Paulo: USP, 2018. Disponível em: <https:// congressousp.fipecafi.org/anais/Anais2018/ArtigosDownload/1023. pdf>. Acesso em: 18 nov. 2020.

COSTA, D. R. M. Rating de cooperativas agropecuárias: uma contribuição metodológica. 2005. Dissertação (Mestrado em Economia Aplicada) - Escola Superior de Agricultura Luiz de Queiroz, Universidade de São Paulo, Piracicaba, 2005. Disponível em: <http://www.sbicafe. ufv.br/bitstream/handle/123456789/11996/Dissertacao_Davi\%20 Rogerio\%20de\%20Moura\%20Costa. pdf?sequence=1\&isAllowed=y $>$. Acesso em: 18 nov. 2020.

CREAR, S. Co-operative banks, credit unions and the financial crisis (Paper for the UN Expert Group Meeting on Co-operatives). New York: World Council of Credit Union, 2009. Disponível em: <https:// www.un.org/esa/socdev/egms/docs/2009/cooperatives/Crear.pdf>. Acesso em: 18 nov. 2020.

CUCINELLI, D. et al. Credit Risk in European Banks: The Bright Side of the Internal Ratings Based Approach. Journal of Banking and finance, v. 9, n. 3, p. 213-229, 2018.

DANTAS, J. A. et al. Determinantes do grau de evidenciação de risco de crédito pelos bancos brasileiros. Revista Contabilidade \& Finanças, v. 21, n. 52 , p. $1-27,2010$.

FARRELL, M. J. The measurement of productive efficiency. Journal of the Royal Statistical Society, v. 120, n. 3, p. 253-290, 1957.

FERREIRA, M. A. M. et al. Previsão de risco de crédito para definição do perfil de clientes de um banco de varejo. Revista de Negócios, v. 16, n. 2, p. 47-64, 2011.

FIORDELISI, F.; MARQUES-IBANEZ, D.; MOLYNEUX, P. Efficiency and risk in European banking. Journal of Banking \& Finance, v. 35, n. 5 , p. 1315-1326, 2011.

FRANCISCO, J. R. D. S.; AMARAL, H. F.; BERTUCCI, L. A. Risco de crédito em cooperativas: uma análise com base no perfil do cooperado. Sociedade, Contabilidade e Gestão, v. 7, n. 2, p. 137149, 2012.

FREITAS, A. F. D.; AMARAL, I. D. C.; BRAGA, M. J. A influência dos riscos de liquidez e de crédito no processo de conversão das cooperativas de crédito rural em cooperativas de crédito de livre admissão: um estudo de caso. Revista de Contabilidade e Organizações, v. 2, n. 4, p. 126-147, 2008.

GISCHER, H.; JÜTTNER, D. J. Profitability and competition in banking markets: an aggregative cross country approach. Madeburgo: Otto von Guericke University Magdeburg, 2001. Disponível em: <https://pdfssemanticscholar.org/043d/ f11a0bc1718fb4382b608dd930937704685b.pdf >. Acesso em: 18 nov. 2020.
GLASS, J. C. et al. Cooperative bank efficiency in Japan: a parametric distance function analysis. The European Journal of Finance, v. 20, n. 3, p. 291-317, 2014.

HACKBARTH, D.; MIAO, J.; MORELLEC, E. Capital structure, credit risk, and macroeconomic conditions. Journal of Financial Economics, v. 82, n. 3, p. 519-550, 2006.

HOFF, A. Second stage DEA: comparison of approaches for modelling the DEA score. European Journal of Operational Research, v. 181 , n. 1, p. 425-435, 2007.

HOU, X.; WANG, Q.; ZHANG, Q. Market structure, risk taking, and the efficiency of Chinese commercial banks. Emerging Markets Review, v. 20, p. 75-88, set. 2014 .

HUSCHER, P. F. Modelo de rating para avaliação de cooperativas de crédito. 2017. Dissertação (Mestrado em Gestão de Cooperativas) Pontifícia Universidade Católica do Paraná, Curitiba, 2017.

IMBIEROWICZ, B.; RAUCH, C. The relationship between liquidity risk and credit risk in banks. Journal of Banking \& Finance, v. 40, p. $242-$ 256, mar. 2014.

JORION, P. Value at risk: a nova fonte de referência para a gestão do risco financeiro. 2. ed. São Paulo: Bolsa de Mercadorias e Futuros, 2003.

KAUPELYTÈ, D.; MCCARTHY, O. Risk management in Lithuanian and Irish credit unions: trends and impacts on credit union development. Journal of Rural Cooperation, v. 34, n. 2, p. 179-194, 2006.

KAR, S.; DEB, J. Efficiency determinants of microfinance institutions in India: an indicative DEA approach. Abhigyan, v. 36, n. 2, p. 1-11, 2018.

KRAKAH, A. K.; AMEYAW, A. The determinants of bank's profitability in Ghana: the case of Merchant Bank Ghana Limited (MBG) and Ghana Commercial Bank (GCB). 2010. Master Thesis (Master Degree in Business Administration) - School of Management, Blekinge Institute of Technology, Karlshamn, 2010.

LIMA, F. G. et al. Os determinantes dos ratings de crédito dos bancos brasileiros. Revista de Administração Contemporânea, v. 22, n. 2, p. 178-200, 2018.

MARCUCCI, J.; QUAGLIARIELLO, M. Asymmetric effects of the business cycle on bank credit risk. Journal of Banking \& Finance, v. 33, n. 9, p. 1624-1635, 2009.

MELO, E. S.; LIMA, J. E. Análise do risco de liquidez em cooperativas de crédito de economia solidária: o caso do sistema Cresol. Gestão Contemporânea, v. 17, p. 104-128, 2015.

MOTTA, A. Na contramão dos bancos, cooperativas de crédito abrem agências. Exame, São Paulo, 02 fev. 2018. Disponível em: <https:// exame.com/seu-dinheiro/na-contramao-dos-bancos-cooperativasde-credito-abrem-agencias/>. Acesso em: 18 nov. 2020.

MUSAU, S.; MUATHE, S.; MWANGI, L. Financial inclusion, bank competitiveness and credit risk of commercial banks in Kenya. International Journal of Financial Research, v. 9, n. 1, p. 203-218, 2018.

PASTOR, J. M.; SERRANO, L. Efficiency, endogenous and exogenous credit risk in the banking systems of the Euro area. Applied Financial Economics, v. 15, n. 9, p. 631-649, 2005.

PEÑA, C. R. Um modelo de avaliaçăo da eficiência da administraçăo pública através do método análise envoltória de dados (DEA). Revista de Administração Contemporânea, v. 12, n. 1, p. 83-106, 2008. 
PEREIRA, J. M. Gestão do risco operacional: uma avaliação do novo Acordo de Capitais-Basileia II. Revista Contemporânea de Contabilidade, v. 6, n. 3, p. 103-124, 2006.

PODPIERA, J.; WEILL, L. Bad luck or bad management? Emerging banking market experience. Journal of Financial Stability, v. 4, n. 2, p. $135-148,2008$

SAEED, M.; IZZELDIN, M. Examining the relationship between default risk and efficiency in Islamic and conventional banks. Journal of Economic Behavior \& Organization, v. 132, n. 12.2016, p. 127-154, 2014.

SALAS, V.; SAURINA, J. Credit risk in two institutional regimes: Spanish commercial and savings banks. Journal of Financial Services Research, v. 22, n. 3, p. 203-224, 2002

SANG, M. N. Income diversification and bank efficiency in Vietnam. Journal of Economics and Development, v. 19, n. 3, p. 52-67, 2017.

SARMIENTO, M.; GALÁN, J. E. The influence of risk-taking on bank efficiency: evidence from Colombia. Emerging Markets Review, v. 32, p. 52-73, set. 2017.

SATHYE, M. The impact of internet banking on performance and risk profile: evidence from Australian credit unions. Journal of Banking Regulation, v. 6, n. 2, p. 163-174, 2005.

SILVA, R. A. Performance financeira da carteira na avaliação de modelos de análise e concessão de crédito: uma abordagem baseada em aprendizagem estatística. 2014. Tese (Doutorado em Administração de Organizações) - Faculdade de Economia, Administração e Contabilidade de Ribeirão Preto, University of São Paulo, Ribeirão Preto, 2014. Disponível em: <http://www.teses.usp. br/teses/disponiveis/96/96132/tde-04112014-165830/en.php>.

Acesso em: 18 nov. 2020.

SOUZA, U. R. D.; BRAGA, M. J.; FERREIRA, M. A. M. Fatores associados à eficiência técnica e de escala das cooperativas agropecuárias paranaenses. Revista de Economia e Sociologia Rural, v. 49, n. 3, p. 573-597, 2011.

STAUB, R. B.; SOUZA, G. D. S.; TABAK, B. M. Evolution of bank efficiency in Brazil: a DEA approach. European Journal of Operational Research, v. 202 , n. 1 , p. $204-213,2010$
STIGLITZ, J. E. The role of the state in financial markets. The World Bank Economic Review, v. 7, n. 1, p. 19-52, 1993

STUCHI, L. G. Quantificação de risco de crédito: uma aplicação do modelo CreditRisk+ para financiamento de atividades rurais e agroindustriais. 2004. Dissertação (Mestrado em Economia Aplicada) - Escola Superior de Agricultura Luiz de Queiroz, Universidade de São Paulo, Piracicaba, 2004. Disponível em: <http://www.teses.usp. br/teses/disponiveis/11/11132/tde-13072004-151006/en.php>. Acesso em: 18 nov. 2020.

SUN, L.; SUN, X.; RABARISON, M. K. Performance efficiency evaluation of US Credit Unions around the 2009 global recession: a data envelopment analysis approach. The Journal of Business Inquiry, v. 18, n. 2, p. 120-142, 2018.

TABAK, B. M.; CRAVEIRO, G. L.; CAJUEIRO, D. O. Eficiência bancária e inadimplência: testes de causalidade (Trabalho para discussão do Bacen n. 220). Brasília, DF: Banco do Brasil, 2010. Disponível em: <https://www.bcb.gov.br/pec/wps/port/TD220.pdf>. Acesso em: 18 nov. 2020.

TAN, Y.; ANCHOR, J. The impacts of risk-taking behaviour and competition on technical efficiency: evidence from the Chinese banking industry. Research in International Business and Finance, v. 41, p. 90-104, out. 2017.

TAN, Y.; FLOROS, C. Risk, competition and efficiency in banking: evidence from China. Global Finance Journal, v. 35, p. 223-236, fev. 2018.

TOLEDO, J. R.; KROENKE, A.; SOTHE, A. Impacto da crise do subprime na provisão do risco de crédito dos maiores bancos nacionais. Revista Brasileira de Gestão de Negócios, v. 11, n. 32, p. 248-259, 2009.

TURNER, H.; WINDLE, R.; DRESNER, M. North American containerport productivity: 1984-1997. Transportation Research Part E - Logistics and Transportation Review, v. 40, n. 4, p. 339-356, 1997.

VIEIRA, L. K. Diversificação de receitas e o desempenho das cooperativas de crédito brasileiras. 2016. Dissertação (Mestrado em Ciências Contábeis) - Universidade Federal de Minas Gerais, Belo Horizonte, 2016. Disponível em: <http://www.bibliotecadigital.ufmg. br/dspace/handle/1843/BUOS-BADJMR>. Acesso em: 18 nov. 2020.

WORTHINGTON, A. C. Measuring technical efficiency in Australian credit unions. The Manchester School, v. 67, n. 2, p. 231-248, 1999. 
Lua Syrma Zaniah Santos

ORCID: https://orcid.org/0000-0003-3829-9530

Mestra em Controladoria e Contabilidade pela Universidade Federal de Minas Gerais (UFMG), Belo Horizonte - MG, Brasil. E-mail: Iuasyrma@gmail.com

Valéria Gama Fully Bressan

ORCID: https://orcid.org/0000-0001-6340-9717

Doutora em Economia Aplicada e professora associada da Faculdade de Ciências Econômicas da Universidade Federal de Minas Gerais (UFMG), Belo Horizonte - MG, Brasil. E-mail: valeriafully@ufmg.br

Vilmar Rodrigues Moreira

ORCID: https://orcid.org/0000-0003-1796-6752

Doutor em Administração e professor titular da Escola de Negócios da Pontifícia Universidade Católica do Paraná (PUCPR), Curitiba - PR, Brasil.

E-mail:vilmar.moreira@pucpr.br

Romeu Eugênio de Lima

ORCID: https://orcid.org/0000-0003-0464-1115

Doutor em Administração pela Universidade Federal de Minas Gerais (UFMG), Belo Horizonte - MG, Brasil. E-mail: romeu.lima@bcb.gov.br 